\title{
Susceptibility of Strawberry Cultivars and Advanced Selections to Leaf Spot Caused by Mycosphaerella fragariae
}

\author{
Nathalie Delhomez ${ }^{1}$ \\ Ecole Nationale d'Ingénieurs des Travaux Agricoles de Dijon, 21 Olivier de \\ Serre Boulevard, B.P. 48-21802 Quetigny Cedex, France
}

Odile Carisse $^{2}$ and Michel Lareau ${ }^{3}$

Agriculture and Agri-Food Canada Research Station, 430 Gouin Boulevard, St-Jean-sur-Richelieu, Que. J3B 3E6, Canada

\section{Shahrokh Khanizadeh ${ }^{4}$ \\ Department of Plant Science, McGill University, Ste-Anne-de-Bellevue, Que. H9X 3V9, Canada, and Agriculture and Agri-Food Canada Research Station, 430 Gouin Boulevard, St-Jean-sur-Richelieu, Que. J3B 3E6, Canada}

Additional index words. Fragaria $\times$ ananassa, disease evaluation, selection, cultivar

\begin{abstract}
Seventeen strawberry (Fragaria $\times$ ananassa Duchesne) cultivars and six selections were tested under greenhouse conditions for susceptibility to leaf spot induced by Mycosphaerella fragariae (Tul.) Lindau. The level of susceptibility was evaluated based on maximum disease severity and area under the disease progress curve (AUDPC). The 23 genotypes were ranked based on AUDPC and grouped according to their susceptibility. Cluster analysis for AUDPC gave four groups corresponding to low, moderate, high, and very high susceptibility to leaf spot. 'Annapolis', 'Chambly', 'Glooscap', 'Redcoat', and 'Veestar' consistently showed a low level of susceptibility. The selections SJ89700-1 and SJ8518-11 and 'Tribute' showed a very high level of susceptibility, and the remaining cultivars were grouped as either moderately or highly susceptible.
\end{abstract}

Leaf spot, caused by Mycosphaerella fragariae, is a common foliar disease in strawberry in Canada (Fall, 1951) and the United States (Dale and Fulton, 1957; Fulton, 1958; Plakidas, 1965). The symptoms of this disease are small, purple, circular spots that first appear on young leaves. As the spots enlarge, the center becomes brown with distinct red borders. The fungus also may attack the petioles and fruit calyces, causing symptoms similar to those found on the leaves, but lesions on petioles are more elongated than those on leaves (Paulus, 1990). Fruit infection occurs when epidemics are severe, in which case some or all seeds and underlying flesh become discolored, rendering fruits unmarketable (Fulton, 1958).

Because some strawberry breeders incorporated resistance to leaf spot into many cultivars (Janick and Williams, 1959; Nemec, 1971), the disease almost disappeared or stayed secondary in most of the strawberry produc-

Received for publication 3 Aug. 1994. Accepted for publication 26 Dec. 1994. Agriculture Canada contribution no. 335. The cost of publishing this paper was defrayed in part by the payment of page charges. Under postal regulations, this paper therefore must be hereby marked advertisement solely to indicate this fact.

${ }^{1}$ Visiting student.

${ }^{2}$ Research Scientist, Pathologist; to whom reprint requests should be addressed.

${ }^{3}$ Research Scientist, Small Fruit Specialist.

${ }^{4}$ Assistant Professor, Research Scientist, and Breeder. tion areas of Quebec. However, this situation may change because some cultivars recommended for Quebec are susceptible to foliar diseases (Khanizadeh et al., 1992). Leaf spot can be controlled by applying protectant fungicides, but its control mainly depends on using resistant cultivars (Craig, 1979; Maas, 1984). Our objective was to evaluate the susceptibility to leaf spot of 17 cultivars recommended for Quebec and six advanced selections from the Quebec strawberry breeding program.

\section{Materials and Methods}

Plantmaterials. Dormant strawberry plants of each genotype were transplanted into1.0liter (13 $\mathrm{cm}$ in diameter) pots filled with a 1 mineral soil : 1 peatmoss : 1 sand (by volume) mixture. The pots were placed in a greenhouse maintained at 18 to $20 \mathrm{C}$ and with a 12 -h photoperiod. During unsatisfactory natural light conditions, supplementary lighting was supplied by high-pressure sodium lamps (model 400-50; Lumiponic, Boisbriand, Canada; S.H.P.-S.O.; $400 \mathrm{~W}, 70 \mu \mathrm{mol} \cdot \mathrm{m}^{-2} \cdot \mathrm{s}^{-1}$ ) to extend the photoperiod to $12 \mathrm{~h}$. Fertilizer was applied at the time of transplanting with $150 \mathrm{ml}$ of $10 \mathrm{~N}-52 \mathrm{P}-10 \mathrm{~K}$ per plant at $5 \mathrm{~g} \cdot$ liter $^{-1}$ water and 1 week later with $150 \mathrm{ml}$ of $20 \mathrm{~N}-$ 20P-20K per plant at 3 g. liter $^{-1}$ water. The plants were kept in the greenhouse for 3 weeks during May and June and then used for inoculations.
Production of inoculum. Inoculum was produced from an isolate of $M$. fragariae isolated from a diseased strawberry leaf collected in 1992 at the Agriculture Canada Experimental Farm, l'Acadie, Quebec. The fungus was identified based on morphological characters (Mass, 1984); symptoms produced by the isolate on strawberry leaves were used to confirm isolate pathogenicity and virulence. Stock cultures were maintained on potato dextrose agar slants at 3C. Because pathogenicity may be lost during storage, strawberry leaves ('Kent') were inoculated with the pathogen, and the fungus was reisolated following a method described by Carisse and Kushalappa (1989) before we produced inoculum for these experiments. The fungus then was transferred to strawberry leaf agar (SLA) and incubated at room temperature (20 to $25 \mathrm{C}$ ) for 2 weeks. The SLA was prepared as follows: $200 \mathrm{~g}$ (fresh weight) of pesticide-free strawberry leaves were blended in $250 \mathrm{ml}$ of distilled water, autoclaved $5 \mathrm{~min}$, and filtered through two layers of cheesecloth. The solution volume was adjusted to 1 liter. Then, $12 \mathrm{~g}$ of agar (Difco) and $125 \mu \mathrm{g}$ of chlorotetracyclin (Sigma Chemical, St. Louis) were added, and the solution was autoclaved for $20 \mathrm{~min}$ at $100 \mathrm{kPa}$. To increase spore production rapidly, $10 \mathrm{ml}$ of sterile distilled water was poured onto each plate, and a mycelial suspension was made by rubbing the culture with a glass rod to remove the mycelium. The mycelial suspension was inoculated on SLA plates ( $2 \mathrm{ml} /$ plate), and the spore-production plates were incubated at room temperature (20 to 25C) for 1 week. On the day of inoculation, a conidial suspension was prepared from these cultures by pouring $10 \mathrm{ml}$ of a sterile, distilled water and $0.01 \%$ Tween 80 solution into each plate; spores were dislodged by gently rubbing the surface of the colony using a glass rod. The spore suspension then was adjusted to $5 \times 10^{4}$ spores $/ \mathrm{ml}$ with the aid of a haemacytometer (model laFontaine; von Birckhahn International, Germany)

Inoculation. The last two leaves of each plant that emerged unfolded were tagged and inoculated on both surfaces until runoff using an airbrush (model HS-799; Paashe, Harwood Heights, Ill.) operated at $100 \mathrm{kPa}$ of air pressure. Immediately after inoculation, the plants were placed in a mist chamber installed in a greenhouse. The mist was provided by a humidifier (Sovereign, Irvington, N.J.) equipped with a fan that uniformly distributed the mist under a plastic tent. The temperature in the tent, monitored with thermocouples (model CN 4000; Omega, Stamford, Conn.), varied from 18 to $30 \mathrm{C}$; however, temperature was uniform within the tent. The plants were kept in the mist chamber for $96 \mathrm{~h}$ and then relocated to the greenhouse for symptom development. A completely randomized design with 23 genotypes and seven replicates per genotype was used, and the experiment was conducted twice.

Disease evaluation. Beginning 8 days after inoculation, the plants were observed every day, and disease severity (percent leaf area diseased) was estimated using a diagrammatic scale developed for this purpose (Fig. 1). To develop the scale, the surface of a strawberry 
leaf was measured with a planimeter (model LI-3100; LI-COR, Lincoln, Neb.) and photocopied. Then, the leaf's border was traced with a pen on a white sheet of paper and cut out. Dark spots were drawn on the white paper leaf, the dark surface measured, and spots added until the desired surface was obtained. The same procedure was repeated for all percent leaf-area classes. Lesion size and distribution was selected to resemble real symptoms as
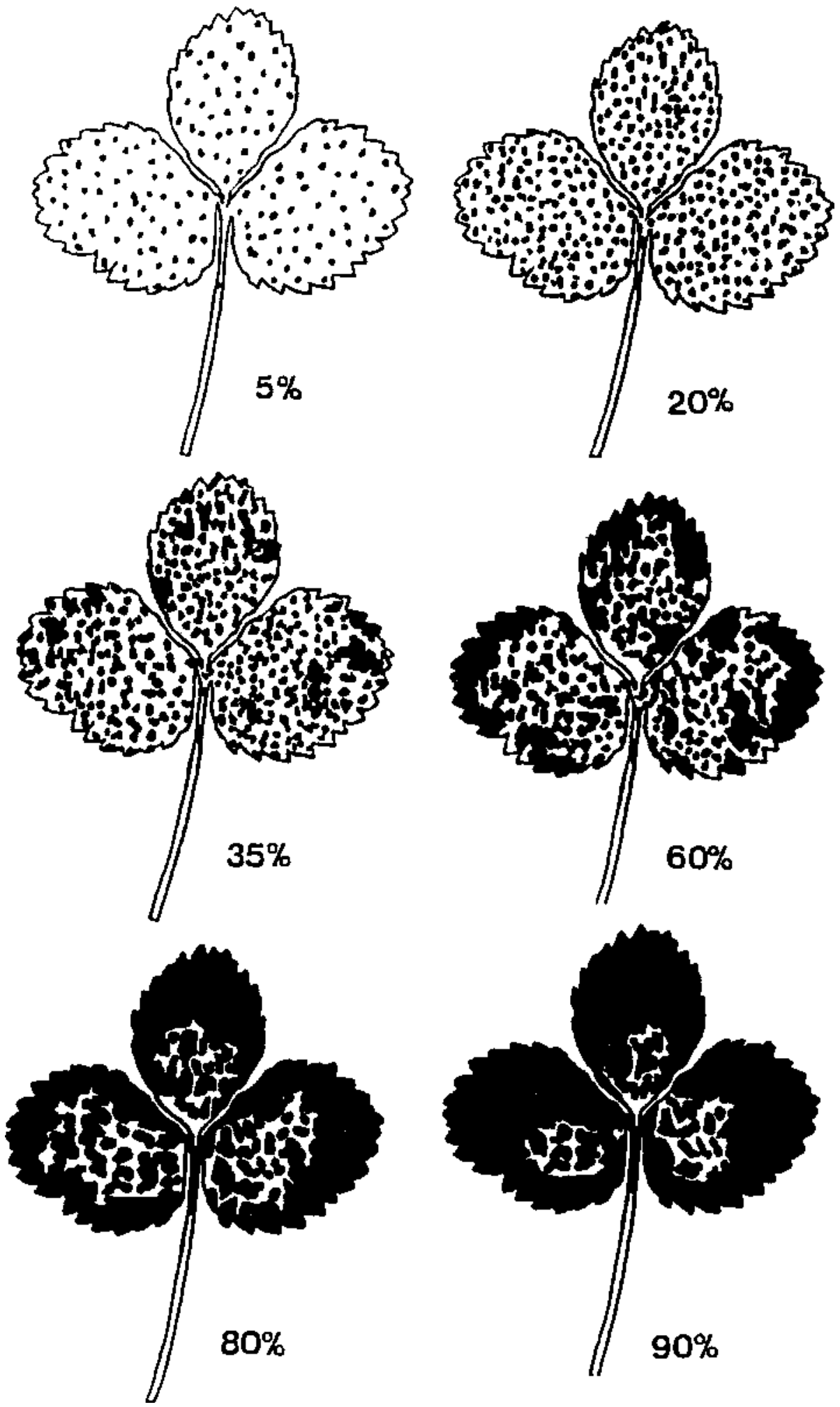

Fig. 1. Diagrammatic scale developed to evaluate the percent leaf area diseased.
(AUDPC). MDS was defined as the maximum percent leaf-area diseased (average of the two inoculated leaves per plant). The AUDPC was calculated from the equation proposed by Shaner and Finney (1977):

, where

$\mathrm{n}=$ the last day of observation, $\mathrm{i}=$ the day of observation, $\mathrm{Y}_{\mathrm{i}}=$ the percent disease at day $\mathrm{i}$ (total of the two inoculated leaves), and $t_{i}-t_{i-1}=$ the interval between each observation. Because observations were done every day, the term $t_{i}-t_{i-1}$ was reduced to the value of one. Because symptoms developed over varying periods, depending on genotype and experimental variation of conditions in the greenhouse between the experiments, and to facilitate comparison with other studies, the AUDPC was expressed as AUDPC per day.

Data analysis. A homogeneity of variance test was conducted to determine whether data from the two experimental repetitions could be pooled (Steel and Torrie, 1980). The analysis of variance was performed using the general linear model procedure of SAS (SAS Institute, 1987), and the least significant difference test was used for means separation. A cluster analysis also was used to group genotypes with similar levels of susceptibility to leaf spot.

\section{Results and Discussion}

The homogeneity of variance test indicated that pooling the data was allowed $(P>$ $0.1)$. 'Annapolis', 'Chambly', 'Glooscap', 'Redcoat', and 'Veestar' were least susceptible ( $\leq 30 \%$ leaf area diseased), and SJ89700-1, SJ8518-11, and 'Tribute' were most suscep-

Table 1. Relative susceptibility of strawberry genotypes to Mycosphaerella fragariae.

\begin{tabular}{lcc}
\hline Genotypes & AUDPC & MDS \\
\hline SJ89700-1 & 6.91 & 76 \\
SJ8518-11 & 6.19 & 67 \\
Tribute & 6.11 & 76 \\
SJ89264-6 & 5.52 & 60 \\
SJ89282-20 & 5.25 & 60 \\
SJ89244-6E & 4.68 & 52 \\
Kent & 4.62 & 56 \\
Micmac & 4.50 & 55 \\
SJ8976-1 & 4.44 & 44 \\
St. Williams & 4.21 & 65 \\
Jewel & 3.96 & 40 \\
Vantage & 3.49 & 53 \\
Settler & 3.43 & 49 \\
Sparkle & 3.41 & 40 \\
Governor Simcoe & 3.35 & 36 \\
Oka & 2.79 & 35 \\
Bounty & 2.58 & 35 \\
Honeoye & 2.45 & 29 \\
Glooscap & 2.06 & 21 \\
Chambly & 1.89 & 18 \\
Annapolis & 1.73 & 26 \\
Veestar & 1.56 & 30 \\
Redcoat & 1.55 & 23 \\
LsD & 1.89 & 13 \\
\hline Area under the disease progress curve cal & \\
\hline
\end{tabular}

${ }^{\mathrm{z} A r e a}$ under the disease progress curve calculated using an equation (see text).

${ }^{y}$ Maximum disease severity (MDS) was defined as the maximum disease severity observed and expressed in percent leaf area diseased (average of the two inoculated leaves per plant). 
tible ( $\geq 60 \%$ leaf area diseased). The remaining genotypes were either moderately susceptible, with $30 \%$ to $40 \%$ of leaf area diseased ('Honeoye', 'Bounty', 'Oka', 'Governor Simcoe', 'Sparkle', 'Settler', and 'Vantage'), or susceptible, with $40 \%$ to $60 \%$ leaf area diseased ('Jewel', 'St. Williams', SJ8976-1, 'Micmac', 'Kent', SJ89244-6E, SJ89282-20, and SJ89264-6) (Table 1).

Cluster analysis was used to group genotypes with similar AUDPC (Fig. 2). The disease progress curves for the genotypes with low susceptibility were flat, indicating that the disease progressed slowly (Fig. 3A): the first symptoms did not appear until 11 to 12 days after inoculation, and the maximum disease severity was $\leq 32 \%$ of leaf area diseased. Disease in genotypes of moderate susceptibility progressed slowly at first, then more rapidly between 13 and 18 days after inoculation, but remained $<55 \%$ of leaf area diseased (Fig. 3B). This pattern was slightly different for 'Settler' and 'Vantage', which were ranked at the upper limit of this group. In genotypes with high susceptibility, disease progressed rapidly such that symptoms appeared as early as 9 or 10 days after inoculation. The maximum disease severity reached was $65 \%$ of leaf area diseased (Fig. 3C). In genotypes of very high susceptibility, disease progress was similar to that of genotypes with high susceptibility, except that $60 \%$ to $78 \%$ of leaf area showed symptoms (Fig. 3D). Because the genotypes were grouped based on AUDPC, genotypes with higher maximum disease severity possibly were put in a group of lower susceptibility. In these cases, even if maximum disease severity was high, the onset of disease was delayed. For example, 'Vantage' with a maximum disease severity of $53 \%$ of leaf area diseased was put in the moderate susceptibility group and SJ8976-1, with 44\% of leaf area diseased, in the high-susceptibility group. The genotypes were grouped based on AUDPC because this characteristic provides a good measure of duration and intensity of disease progress (Kranz, 1974).

The genotypes exhibited different levels of susceptibility based on MDS and the AUDPC. Based on AUDPC, four genotype groups corresponded to low, moderate, high, and very high levels of susceptibility. To our knowledge, this is the first report of leaf spot development for most of the cultivars, except 'Redcoat' and 'Sparkle', which were tested previously (Janick and Williams, 1959; Nemec, 1969, 1971). Nemec (1971) evaluated 'Redcoat' for susceptibility to four races of $M$. fragariae (A-1, A-3, A-4, and A-6) and ranked this cultivar as susceptible. In our study with only one undetermined local race, 'Redcoat' was of low susceptibility with $<25 \%$ of leaf area with symptoms. However, our results for 'Sparkle', with $\approx 25 \%$ of the leaf area diseased, are in accordance with those obtained by Nemec (1969), who conducted greenhouse trials with 27 distinct isolates of $M$. fragariae and ranked 'Sparkle' as highly susceptible to most of the isolates. However, under field conditions, 'Sparkle' was ranked as moderately susceptible (Nemec, 1971). These results are similar

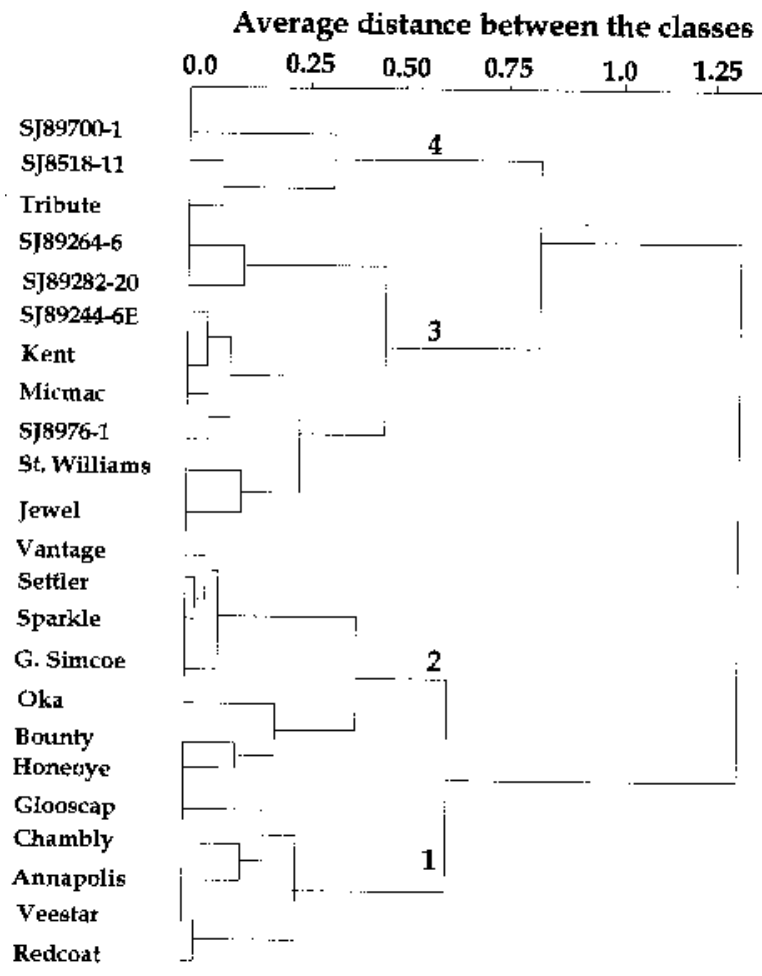

Fig. 2. Cluster analysis of the 23 genotypes based on the area under the disease progress curve.

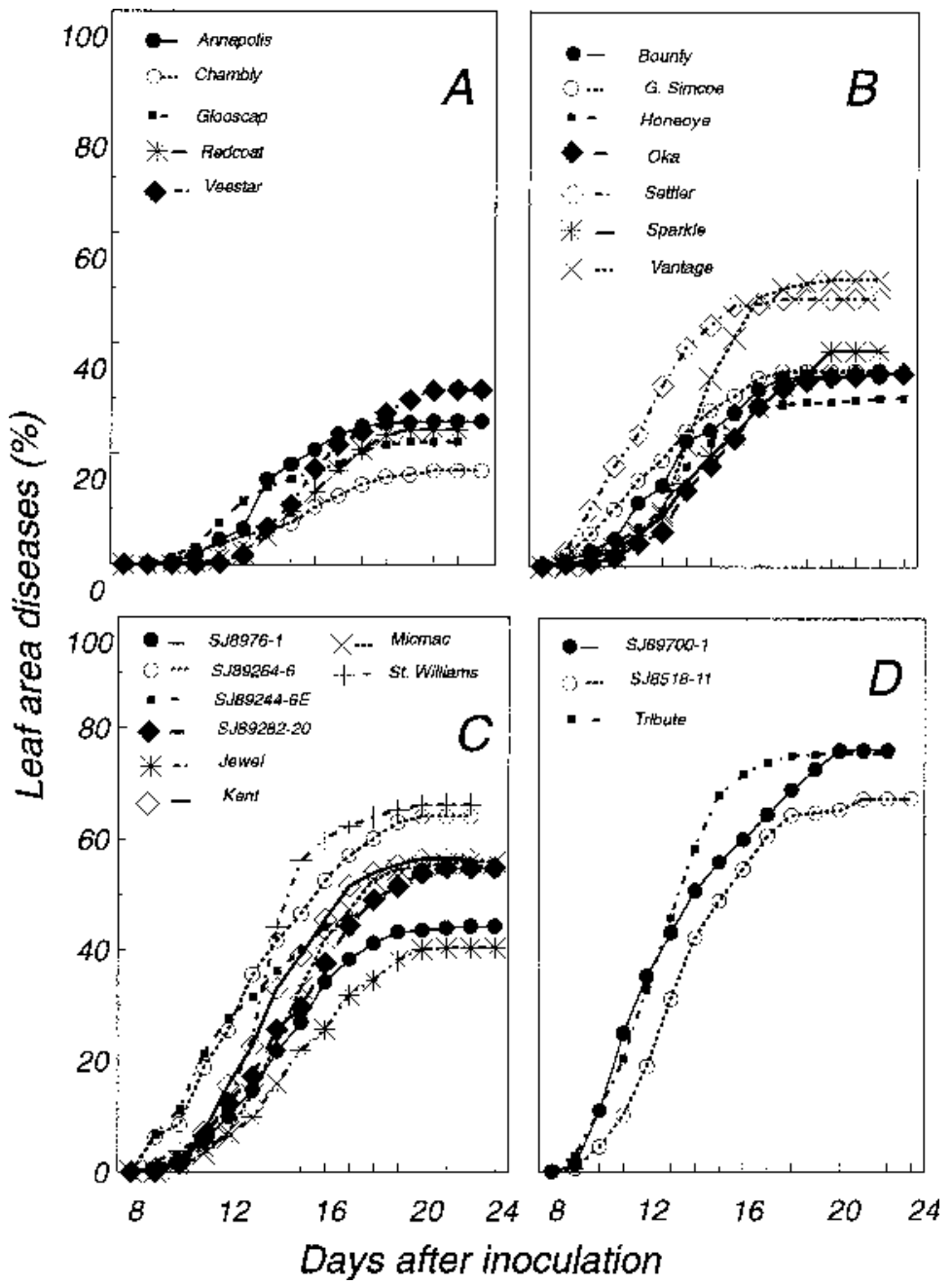

Fig. 3. Disease progress curves, based on percent leaf area disease (average of two leaves) or four susceptibility groups: (A) low, (B) moderate, (C) high, (D) very high. 
to those obtained by Janick and Williams (1959), who considered 'Sparkle' to be moderately susceptible under field conditions. Differences among observations can be explained by the race used, pathogenic variation, and differing environmental conditions during infection (Bolton, 1962; Nemec, 1972). Care must be taken also when comparing field and greenhouse trials. Strawberry cultivars susceptible under artificial inoculation in a greenhouse are not necessarily as susceptible in the field (Plakidas, 1948). Artificial inoculation can be used to confirm apparent field resistance and to screen for resistance in breeding, provided that the appropriate races are used. Hence, 'Annapolis', 'Chambly', 'Glooscap', 'Redcoat', and 'Veestar', with $<25 \%$ of leaf area diseased in a controlled environment, probably will not require fungicide treatments against leaf spot in commercial field production. Our results reflect field experience in Quebec. However, further work is needed to examine the importance of races and other factors, such as the effect of cultivar on sporulation of the pathogen, the initial inoculum sources, and the relationship between disease severity and yield loss.

\section{Literature Cited}

Bolton, A.T. 1962. Pathogenic variation in $\mathrm{Myco}$ sphaerella fragariae. Can. J. Bot. 40:647-650.

Carisse, O. and A.C. Kushalappa. 1989. Effect of media, $\mathrm{pH}$, and temperature on spore production and of inoculum concentration on the number of lesions produced by Cercospora carotae. Phytoprotection 70:119-124.

Craig, D.L. 1979. Culture du fraisier dans l'Est du Canada. Agr. Canada Publ. 1585.

Craig, D.L. 1982. Cultivars de fraisiers pour l'Est du Canada. Agr. Canada Publ. 1744/F.

Dale, J.L. and J.P. Fulton. 1957. Severe loss from strawberry leaf spot in Arkansas in 1957. Plant Dis. Rpt. 41:681-682.

Fall, J. 1951. Studies on fungus parasites of strawberry leaves in Ontario. Can. J. Bot. 29:301-315.

Fulton, R.H. 1958. Studies on strawberry leaf spot in Michigan. Michigan Expt. Sta. Quart. Bul. 40:581-588.

Janick, J. and E.B. Williams. 1959. Resistance of strawberry varieties and selections to leaf spot and scorch. Plant Dis. Rpt. 43:413-415.

Khanizadeh, S., M. Lareau, and D. Buszard. 1992. Strawberry cultivar evaluation in Quebec. J. Small Fruit Viticult. 1(2):23-36.

Kranz, J. 1974. Comparison of epidemics. Annu. Rev. Phytopathol. 12:355-374.

Maas, J.L. 1984. Compendium of strawberry diseases. APS Press, St. Paul, Minn.

Nemec, S. 1969. Determination of leaf spot races in southern Illinois strawberry plantings. Plant Dis. Rpt. 53:94-97.

Nemec, S. 1971. Studies on resistance of strawberry varieties and selections to Mycosphaerella fragariae in southern Illinois. Plant Dis. Rpt. 55:573-576.

Nemec, S. 1972. Temperature effects on $\mathrm{Myco-}$ sphaerella fragariae and strawberry leaf spot development. Plant Dis. Rpt. 56:345-348.

Paulus, A.O. 1990. Fungal diseases of strawberry. HortScience 25:885-889.

Plakidas, A.G. 1948. Strains of Mycosphaerella fragariae. Phytopathology 38:988-992.

Plakidas, A.G. (ed.). 1965. Strawberry diseases. Louisiana State Univ. Press, Baton Rouge.

SAS Institute. 1987. Guide for personal computers, Version 6 ed. SAS Institute, Cary, N.C.

Shaner, G. and R.E. Finney. 1977. The effect of nitrogen fertilization on the expression of slowmildewing resistance in Knox wheat. Phytopathology 67:1051-1056.

Spangelo, P.S. and A.T. Bolton. 1953. Suggested infection scales for roguing strawberry seedlings susceptible to Mycosphaerella fragariae and Diplocarpon earliana. Phytopathology 43:345-347.

Steel, R.G.D. and J.H. Torrie. 1980. Principles and procedures of statistics, A biometrical approach 2nd ed. McGraw-Hill, New York. 